\title{
Effect of lipopolysaccharide on the hemocyte apoptosis of Eriocheir sinensis"
}

\author{
Hai-sheng XU ${ }^{\dagger \S}$, Sun-jian LYU ${ }^{\S}$, Jie-hao XU, Bin-jie LU, Jing ZHAO, Song LI, Yi-qun LI, Yu-yin CHEN ${ }^{\dagger \star}$ \\ (College of Animal Sciences, Zhejiang University, Hangzhou 310058, China) \\ †E-mail: hsxu@zju.edu.cn; chenyy@zju.edu.cn
}

Received Apr. 25, 2015; Revision accepted Sept. 14, 2015; Crosschecked Nov. 24, 2015

\begin{abstract}
In the present study, we investigated the possible toxicity mechanism of lipopolysaccharide (LPS) extracted from Gram-negative bacteria in Eriocheir sinensis hemocytes. Apoptotic hemocytes and reactive oxygen species (ROS) production induced by the LPS were monitored by the combination of flow cytometry and microscope observation. It was shown that LPS induced serious damage on the DNA and morphological changes in hemocytes, including cell shrinkage, fracture of nucleus membrane, margination, condensation and fragmentation of chromatin, and formation of apoptotic bodies indicating obvious hemocyte apoptosis. As compared with the control group, the apoptotic cell ratio increased to $30.61 \%$ and $39.01 \%$ after 1 -h exposure and $57.72 \%$ and $75.01 \%$ after 2 -h exposure to 1 and $10 \mu \mathrm{g} / \mathrm{ml}$ LPS, respectively $(P<0.05)$. Significant outburst of ROS production was observed in LPS-treated hemocytes with approximately $176.6 \%$ of relative dichlorofluorescein mean fluorescence at 1-h exposure, followed by a drastic decline $(P<0.05)$. These results indicated that LPS would induce oxidative stress on hemocytes from $E$. sinensis and cause ROS burst, DNA damage, and subsequently apoptosis. The process of ROS-mediated apoptosis might be one of the potential toxicity mechanisms of LPS on crustacean hemocytes.
\end{abstract}

Key words: Hemocyte, Eriocheir sinensis, Lipopolysaccharide, Apoptosis, Reactive oxygen species doi:10.1631/jzus.B1500098 Document code: A CLC number: Q25

\section{Introduction}

Chinese mitten crab (Eriocheir sinensis), an important commercial freshwater species of aquaculture, has been developed rapidly in the farming scale over the past few decades in China (Gai et al., 2008). Owing to intensive culture and environmental deterioration, however, it frequently suffers from serious infectious diseases caused by bacteria, viruses, parasites, rickettsia-like organisms, and other pathogens, which reduced their production and resulted in

\footnotetext{
Corresponding author

${ }^{\S}$ The two authors contributed equally to this work

* Project supported by the Program for Zhejiang Leading Team of S\&T Innovation (No. 2011R50029) and the National Key Technologies R\&D Program of China (No. 2013BAD20B02)

(D) ORCID: Hai-sheng XU, http://orcid.org/0000-0002-3190-3777

(C) Zhejiang University and Springer-Verlag Berlin Heidelberg 2015
}

economic loss (Lv et al., 2014). In order to lower the risk of these diseases, the enhancement of crab immunity to these invaded pathogens has shown promising sustainable development of aquatic industry.

Unlike vertebrates, E. sinensis possesses only innate immune response system to defend against pathogens, and their circulating hemocytes play key roles in innate immunity, which are directly involved in the processes of recognition and elimination of invading pathogens (Jiravanichpaisal et al., 2006). Loss and damage of circulating hemocytes would depress the immune ability, thus increasing the susceptibility against pathogens. Lipopolysaccharide (LPS), a cell-wall component of Gram-negative bacteria, has been increasingly investigated as a powerful stimulator of cellular immunity in crustaceans and demonstrated to induce degranulation and prophenoloxidase (proPO) release of hemocytes in vivo and 
in vitro. However, previous publications showed that LPS could cause significant decrease in hemocytes in the initial period of treatment in vivo and that such phenomena were attributed to the migration of hemocytes from the hemocoele to the injection sites, hemocyte lysis, and granulocyte degranulation (Johansson and Söderhäll, 1985; le Moullac and Haffner, 2000; van de Braak et al., 2002; Du et al., 2012). Xian et al. (2013) hypothesized that the overproduction of reactive oxygen species (ROS) might be the reason for the death of hemocytes caused by LPS.

Apoptosis is a normal physiological process of cellular self-destruction aiming at eliminating the potentially dangerous cells and allowing the cell to commit suicide (Portt et al., 2011). This process can be triggered by various stimulants, such as virus and bacterium (Sahtout et al., 2001; Chang et al., 2008). In Penaeus monodon, the injection of white spot syndrome virus and yellow head virus induces severe apoptotic response in hemocytes, lymphoid organs, and gills (Sahtout et al., 2001; Khanobdee et al., 2002). In Litopenaeus vannamei, the injection of Vibrio alginolyticus leads to significant decline in the total hemocyte counts, accompanied by the apoptosis of hemocytes being detected simultaneously (Chang et al., 2008; Li and Chen, 2008). In our previous study, we demonstrated that $E$. sinensis experienced drastic decline and rapid recovery in circulating hemocytes after the injection of LPS (Lv et al., 2014). However, no exact evidence was listed to prove whether such a decline in hemocytes was caused by the cell apoptosis.

In the present study, apoptotic cell ratios of LPS-treated hemocytes were investigated by combining the microscope observation and flow cytometry, and the outbreak of ROS production was detected to determine the respiratory burst of apoptotic hemocytes in E. sinensis. The results of this study would help us to better understand the pathological mechanism of LPS on E. sinensis hemocytes as one of the most common stimulators.

\section{Materials and methods}

\subsection{Animals}

Chinese mitten crabs (E. sinensis), about $100 \mathrm{~g}$ on average by weight, were obtained from a commercial crab farm in Chongming County, Shanghai,
China. The crabs were cultivated in a $40-\mathrm{L}$ plastic tank with aerated freshwater flowing at a constant temperature of $(25 \pm 2){ }^{\circ} \mathrm{C}$. Prior to experimental use, the crabs were acclimated for a week and fed with fresh clam once a day. Residual clam was cleaned after feeding the crab for $4 \mathrm{~h}$ and the water was refreshed.

\subsection{Preparation of hemocyte suspension}

A total of $500 \mu \mathrm{l}$ hemolymph in the ventral-sinus cavity was extracted from each crab using a 25 -gage needle and $1.0-\mathrm{ml}$ syringe that contained equal volume of anticoagulant solution $(100 \mathrm{mmol} / \mathrm{L}$ glucose, $26 \mathrm{mmol} / \mathrm{L}$ citric acid, $415 \mathrm{mmol} / \mathrm{L}$ sodium chloride $(\mathrm{NaCl}), 30 \mathrm{mmol} / \mathrm{L}$ sodium citrate, $30 \mathrm{mmol} / \mathrm{L}$ ethylenediaminetetraacetic acid (EDTA); pH 4.6) (Zhang et al., 2010). In order to reduce the interindividual difference, the hemolymph obtained from five crabs was pooled together. The collected hemolymph was centrifuged at $1000 \mathrm{r} / \mathrm{min}$ at $4{ }^{\circ} \mathrm{C}$ for $5 \mathrm{~min}$ to obtain an accumulation of hemocyte pellet. The hemocyte pellet was resuspended into a 1-ml L-15 medium (Cat. No. L5520, Sigma-Aldrich, Gillingham, UK) after removing the supernatant.

\subsection{4',6-Diamidino-2-phenylindole (DAPI) staining}

Apoptotic morphology of hemocytes was investigated by staining the cells with the fluorescent DNA-binding dye DAPI. Hemocyte suspension was diluted with L-15 medium into a final concentration of $1 \times 10^{6}$ cells $/ \mathrm{ml}$ and then seeded into six-well plates (Corning Costar Corp, Corning, New York, USA). Hemocytes were incubated at $26{ }^{\circ} \mathrm{C}$ without $5 \%$ carbon dioxide in a model incubator (EYELA LTI-700, Japan) for $12 \mathrm{~h}$. Then, $10 \mu \mathrm{l}$ LPS $(100 \mu \mathrm{g} / \mathrm{ml})$ was added into the culture medium to form a final concentration of $1 \mu \mathrm{g} / \mathrm{ml}$ LPS. After being treated with LPS for $0,4,8$, and $16 \mathrm{~h}$, the cells were rinsed with phosphate-buffered saline $(0.1 \mathrm{~mol} / \mathrm{L}, \mathrm{pH} 7.4)$ and fixed in $4 \%$ paraformaldehyde for $15 \mathrm{~min}$, followed by incubation with $1 \mu \mathrm{g} / \mathrm{ml}$ of DAPI for $15 \mathrm{~min}$. DAPI-stained hemocyte morphology was observed using a fluorescent microscope (ECLIPSE Ti, Nikon, Japan).

\subsection{Transmission electron microscopic observation}

The hemocyte suspension was incubated with LPS $(1 \mu \mathrm{g} / \mathrm{ml})$ for $2 \mathrm{~h}$ and then centrifuged at $1000 \mathrm{r} / \mathrm{min}$ at 
$4{ }^{\circ} \mathrm{C}$ for 5 min to remove the supernatant. The collected hemocyte pellets were fixed with $2.5 \%$ glutaraldehyde in phosphate buffer ( $\mathrm{pH} 7.0)$ overnight and then post-fixed with $0.01 \mathrm{~g} / \mathrm{ml} \mathrm{OsO}_{4}$ in phosphate buffer $(\mathrm{pH}$ 7.0) for $1 \mathrm{~h}$. The pellets were dehydrated by a gradient of ethanol and acetone and subsequently embedded with resin to form ultrathin sections. The resulting sections were stained with uranyl acetate and alkaline lead citrate and observed using a transmission electron microscope (TEM; Hitachi Model H-7650, Japan).

\subsection{DNA fragmentation assay}

Primary cultured hemocytes were incubated with LPS $(1 \mu \mathrm{g} / \mathrm{ml})$ for $0,2,4,8,16$, and $24 \mathrm{~h}$. The broken DNA fragmentation was collected by Apoptotic DNA Ladder Detection Kit (Beyotime Biotech, China) according to the manufacturer's instruction. Eluents containing DNA fragments were analyzed via $2 \%$ $(0.02 \mathrm{~g} / \mathrm{ml})$ agarose gel electrophoresis with ethidium bromide staining and then observed under an ultraviolet (UV) transilluminator (GeneGenius Super 12; Syngene, UK). To determine the impact of LPS concentration on DNA breakage, hemocytes were cultured with indicated LPS concentrations $(0,0.1,1$, and $10 \mu \mathrm{g} / \mathrm{ml}$ ) for $4 \mathrm{~h}$, and then the broken DNA fragments were collected and analyzed.

\subsection{Annexin V-fluorescein isothiocyanate (V-FITC)/ propidium iodide (PI) assay}

The hemocyte suspension was challenged with different LPS concentrations ( 1 and $10 \mu \mathrm{g} / \mathrm{ml})$ and incubated at $26^{\circ} \mathrm{C}$ for the indicated time points. One group was set as the control with hemocytes challenged by stroke-physiological saline solution at the same time point. At 0,1 , and $2 \mathrm{~h}$ after the LPS stimulation, hemocytes were collected and stained twice with Annexin V-FITC and PI according to the manufacturer's instruction (No. 130-92-052; Miltenyi Biotec, Germany). For determining the apoptotic hemocyte ratio, a total of 10000 cells were analyzed by flow cytometry (FC 500 MCL; Beckman Coulter, USA) and repeated three times for each group.

\subsection{Analysis of ROS production}

Cell-permeant probe 2',7'-dichlorodihydrofluorescein diacetate (DCFH-DA; Sigma, St. Louis, MO, USA) was used to monitor the level of ROS production. The hemocyte suspension was treated with LPS $(10 \mu \mathrm{g} / \mathrm{ml})$ and incubated with $1 \mu \mathrm{mol} / \mathrm{L}$ DCFH-DA at $26{ }^{\circ} \mathrm{C}$ for the indicated time points. The other group was set as the control with hemocytes incubated with strokephysiological saline solution and DCFH-DA at the same time point. At 0,1 , and $2 \mathrm{~h}$ after the LPS stimulation, hemocyte pellets were collected by centrifuging at $1000 \mathrm{r} / \mathrm{min}$ at $4{ }^{\circ} \mathrm{C}$ for $5 \mathrm{~min}$. The pellets were washed with L-15 medium twice and resuspended to obtain a final concentration of $1 \times 10^{6}$ cells $/ \mathrm{ml}$. The intensity of dichlorofluorescein (DCF) fluorescence in 10000 cells was analyzed using a flow cytometry (FC 500 MCL, Beckman Coulter, USA), and the experiment was repeated three times.

Primary cultured hemocytes were incubated at $26{ }^{\circ} \mathrm{C}$ for $12 \mathrm{~h}$ prior to experiment. The hemocytes were challenged with LPS $(10 \mu \mathrm{g} / \mathrm{ml})$ and incubated with $1 \mu \mathrm{mol} / \mathrm{L}$ DCFH-DA at room temperature. At 0 , 10,20 , and 30 min post stimulation, hemocytes were observed and photographed using a laser confocal microscopy (Zeiss LSM 780, Zeiss, Germany).

\subsection{Statistical analysis}

Results were expressed as mean \pm standard deviation (SD). SPSS software (11.0) was used for statistical analyses. The effect of treatments was statistically analyzed using the one-way analysis of variance (ANOVA), and the differences were considered to be significant at $P<0.05$.

\section{Results}

\subsection{Morphological observation of LPS-induced hemocytes}

To assess morphological change, the hemocytes challenged with $1 \mu \mathrm{g} / \mathrm{ml}$ LPS were observed under a fluorescence microscope stained with DAPI and a TEM. As shown in Fig. 1, the hemocytes display cell shrinkage, formation of apoptotic bodies, and nuclear fragmentation, which are similar to the morphological changes observed in cells undergoing apoptosis. After being treated with LPS for $4 \mathrm{~h}$, the hemocytes appeared with cell shrinkage, and the ratio of hemocytes undergoing apoptosis increased with time (Fig. 1b). After being treated for $24 \mathrm{~h}$, nearly all the hemocytes underwent apoptosis process with clear fractured nucleus (Fig. 1b). In the saline-treated group, a few apoptotic hemocytes were observed at $24 \mathrm{~h}$. 

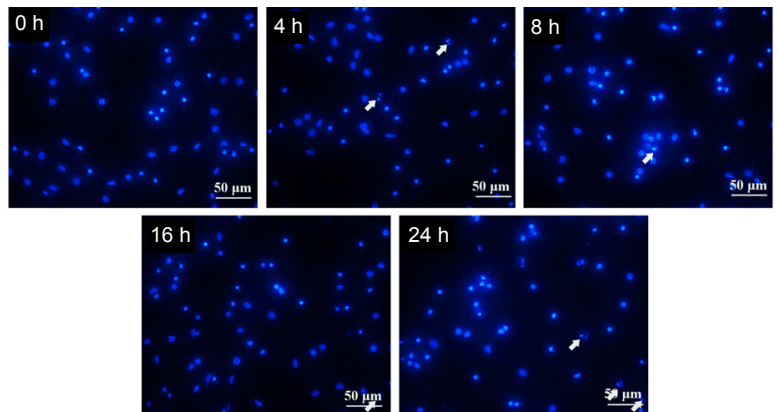

(a)
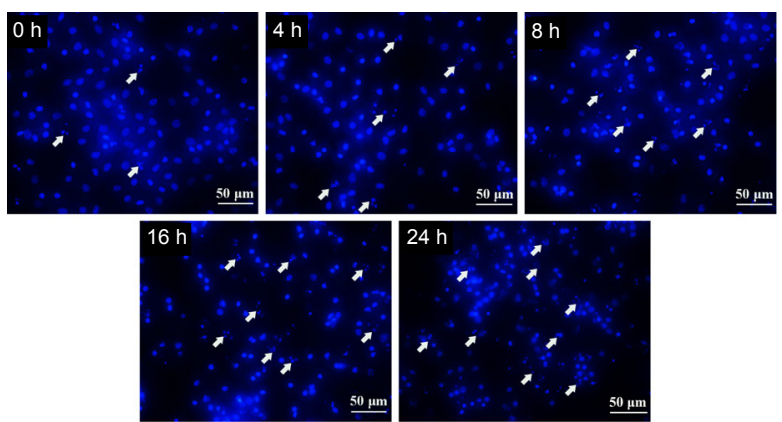

(b)

Fig. 1 Observation of saline-induced (a) and LPS-induced (b) hemocytes of $E$. sinensis by fluorescence microscopy with DAPI staining

Arrows indicate the apoptotic hemocytes with fractured nucleus
In TEM observation, the saline-treated control hemocytes showed normal appearance with integrated nucleus membrane, healthy mitochondria, and non-edged chromatin (Fig. 2b). However, after induction of $1 \mu \mathrm{g} / \mathrm{ml}$ LPS for $2 \mathrm{~h}$, a large number of hemocytes exhibited a series of morphological changes during apoptosis (Fig. 2a), and the hemocytes at different stages of apoptosis are displayed in Figs. 2c-2f. As shown in Fig. 2c, challenging with LPS led to an obvious irregular condensation and edged chromatin of hemocytes. The hemocytes then displayed the fragmented chromatin and fractured nucleus membrane (Fig. 2d). Finally, apoptotic bodies were formed and the mitochondria were slightly swollen (Figs. 2e-2f).

\subsection{DNA fragmentation analysis}

To qualitatively assess the DNA fragments, $2 \%$ agarose gel electrophoresis was carried out on the isolated DNA sample from hemocytes treated with LPS at $1 \mu \mathrm{g} / \mathrm{ml}$ for $0,2,4,8,16$, and $24 \mathrm{~h}$ and in different LPS concentrations $(0,0.1,1$, and $10 \mu \mathrm{g} / \mathrm{ml})$ for $4 \mathrm{~h}$. The results showed that typical characteristics of internucleosomal DNA ladder patterns were detected in the extracted DNA from the hemocytes challenged

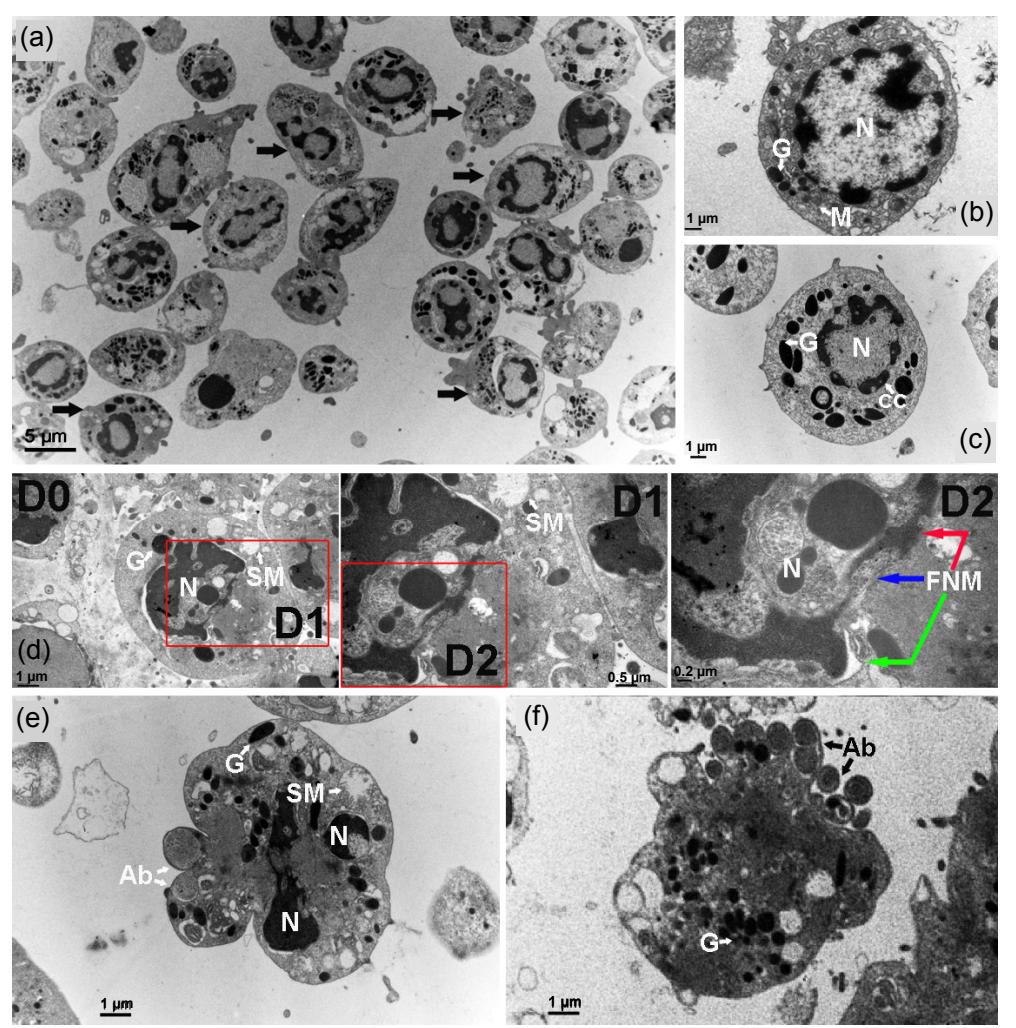

Fig. 2 Morphological observation of LPSinduced hemocytes from $E$. sinensis under TEM

(a) Overview of LPS-induced hemocytes, $3000 \times$. (b) Healthy hemocytes, $10000 \times$. (c)-(f) LPS-induced hemocytes in the different stages of cell apoptosis: (c) hemocytes with chromatin condensation, $10000 \times$; (d) hemocytes with fractured nucleus membrane (D0 12000×, D1 25000×, and D2 $40000 \times$ ); (e) hemocytes with nucleus fragmentation and forming apoptotic bodies $12000 \times$; (f) apoptotic bodies released from the hemocytes $12000 \times$. The arrows stained with blue, green, and red indicate the unruptured, separated, and dissolved double karyotheca, respectively. Black allows indicate the apoptotic haemocytes. G, granule; $\mathrm{N}$, cell nuclear; $\mathrm{M}$, mitochondrion; SM, swelling mitochondrion; Ab, apoptotic body; $\mathrm{CC}$, chromatin condensation; FNM, fractured nucleus membrane (Note: for interpretation of the references to color in this figure legend, the reader is referred to the web version of this article) 
with LPS, indicating that the LPS-treated hemocytes underwent apoptosis (Fig. 3). Fig. 3b shows that DNA-cleaved products with ladder patterns in the nucleus appeared after $4-\mathrm{h}$ stimulation of LPS $(1 \mu \mathrm{g} / \mathrm{ml})$ and that the DNA-cleaved products acclimated significantly at $24 \mathrm{~h}$. In addition, we found that high concentration of LPS $(10 \mu \mathrm{g} / \mathrm{ml})$ intended to induce easier accumulation of DNA fragments as compared with low concentration of LPS $(0.1$ and $1 \mu \mathrm{g} / \mathrm{ml}$; Fig. 3c) and that no significant fragments were detected in the saline group (Fig. 3a).

\subsection{Apoptotic cell ratio analysis by flow cytometry}

As shown in Fig. 4, the hemocytes of E. sinensis could be divided into R2, R3, and R4 types by the flow cytometry. The $\mathrm{R} 2$ hemocytes with a ratio of $65.04 \%$ were the prominent hemocytes with large size and small amount of granules, the R3 hemocytes with a ratio of $23.28 \%$ were in small size and contained few granules, and the $\mathrm{R} 4$ hemocytes with a ratio of $6.64 \%$ owned a medium size and contained various quantities of granules.
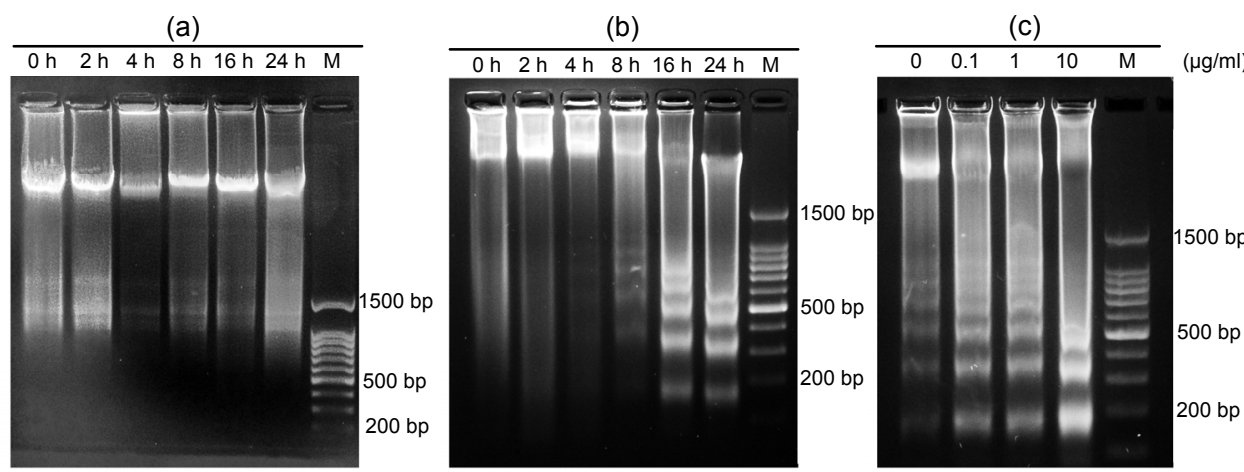

Fig. 3 Assay of DNA fragmentation of saline- and LPS-induced hemocytes by $2 \%$ agarose gel electrophoresis (a) Hemocytes were incubated with saline for different time points. (b) Hemocytes were incubated with $1 \mu \mathrm{g} / \mathrm{ml}$ LPS for different time points. (c) Hemocytes were incubated with different concentrations of LPS for $4 \mathrm{~h}$. M: marker, 100 bp DNA ladder marker

(a)
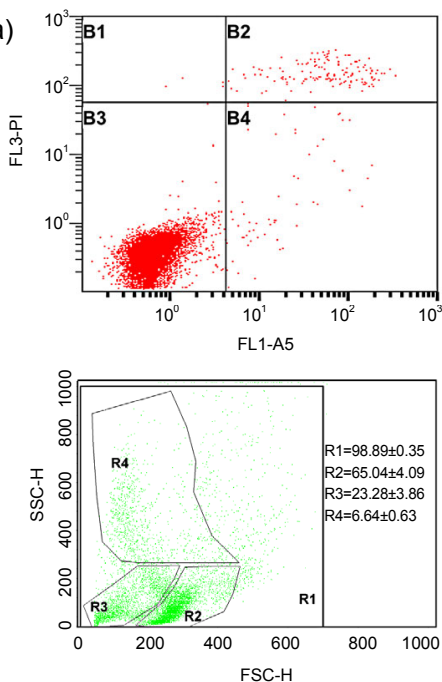

(d)

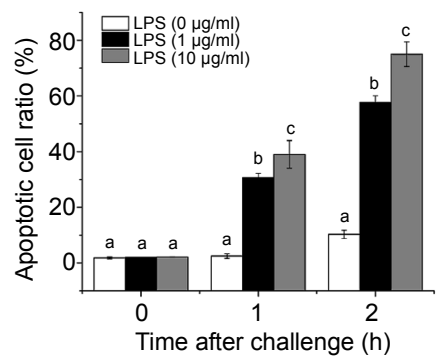

(b)
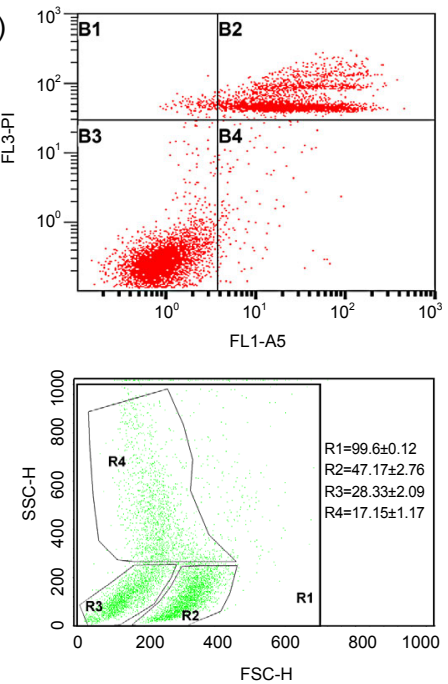

(c)
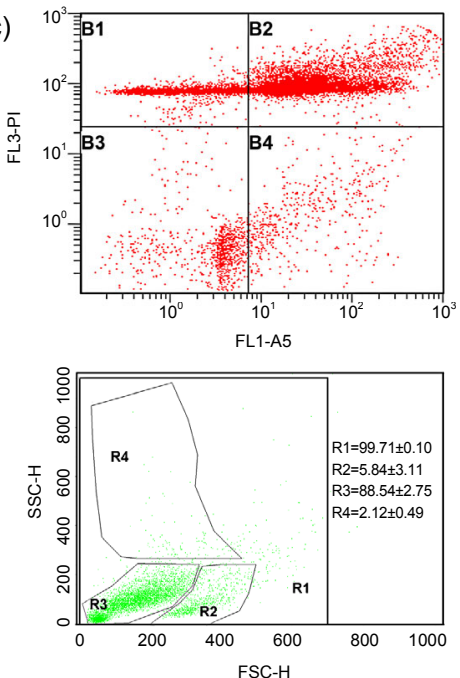

Fig. 4 Annexin V-FITC/PI assay of hemocytes from $E$. sinensis by flow cytometry after exposure to $10 \mu \mathrm{g} / \mathrm{ml} \mathrm{LPS}$

(a) 0-h exposure; (b) 1-h exposure; (c) 2-h exposure. (d) Apoptosis hemocyte ratio after exposure to 1 and $10 \mu \mathrm{g} / \mathrm{ml}$ LPS for different time points. Data were represented as mean \pm standard deviation (SD) of the results from three independent experiments. Data in the same time point with different letters were significantly different among treatments $(P<0.05)$ 
At the beginning, the percentages of apoptotic hemocytes in the control group, $1 \mu \mathrm{g} / \mathrm{ml}$ LPS-treated group, and $10 \mu \mathrm{g} / \mathrm{ml}$ LPS-treated group were $1.86 \%$, $1.99 \%$, and $2.12 \%$, respectively. No significant difference in the percentages of apoptotic hemocytes was detected among two treatment groups of LPS and the control group $(P>0.05)$. Challenging with LPS led to a significant increase in apoptotic hemocyte ratio, and most apoptotic hemocytes were considered to be late apoptotic cells. As compared with the control group, the apoptotic hemocyte ratio increased significantly to $30.61 \%$ and $39.01 \%$ after 1 -h exposure and $57.72 \%$ and $75.01 \%$ after 2 -h exposure to 1 and $10 \mu \mathrm{g} / \mathrm{ml}$ LPS, respectively $(P<0.05)$. In addition, the ratio of cells in R2 decreased drastically with $5.84 \%$ of hemocytes detected after 2-h exposure to $10 \mu \mathrm{g} / \mathrm{ml}$ LPS, whereas the ratio of cells in R3 increased to $88.54 \%$.

\subsection{ROS production of LPS-induced hemocytes}

To determine whether ROS was involved in LPS-induced cell apoptosis, we measured the cellular
ROS by using an ROS-sensitive fluorometric probe, DCFH-DA. As shown in Fig. 5, the hemocytes of $E$. sinensis were divided into two subpopulations containing different DCF mean fluorescences (Fig. 5a). After 1-h exposure to $10 \mu \mathrm{g} / \mathrm{ml} \mathrm{LPS}$, the ROS production increased significantly as compared with the control group $(P<0.05)$, and the relative DCF mean fluorescence (compared with the DCF mean fluorescence at $0 \mathrm{~h}$ ) of hemocytes increased to $176.6 \%$ (Fig. 5d). After $2 \mathrm{~h}$, the ROS production of LPStreated hemocytes drastically decreased to $34.0 \%$, which was significantly lower than that of the control group $(P<0.05)$. Based on the laser confocal microscopy observation, nearly all the hemocytes could be marked with DCFH-DA by the hypofluorescence detected within the cells. Challenged with $10 \mu \mathrm{g} / \mathrm{ml}$ LPS for $10 \mathrm{~min}$, an outburst of ROS production was observed through the bright fluorescent signal detected within hemocytes, especially in granule-containing hemocytes (Fig. 6). In the post LPS stimulation range from 20 to $30 \mathrm{~min}$, a time-dependent significant decrease was observed in ROS production within hemocytes.
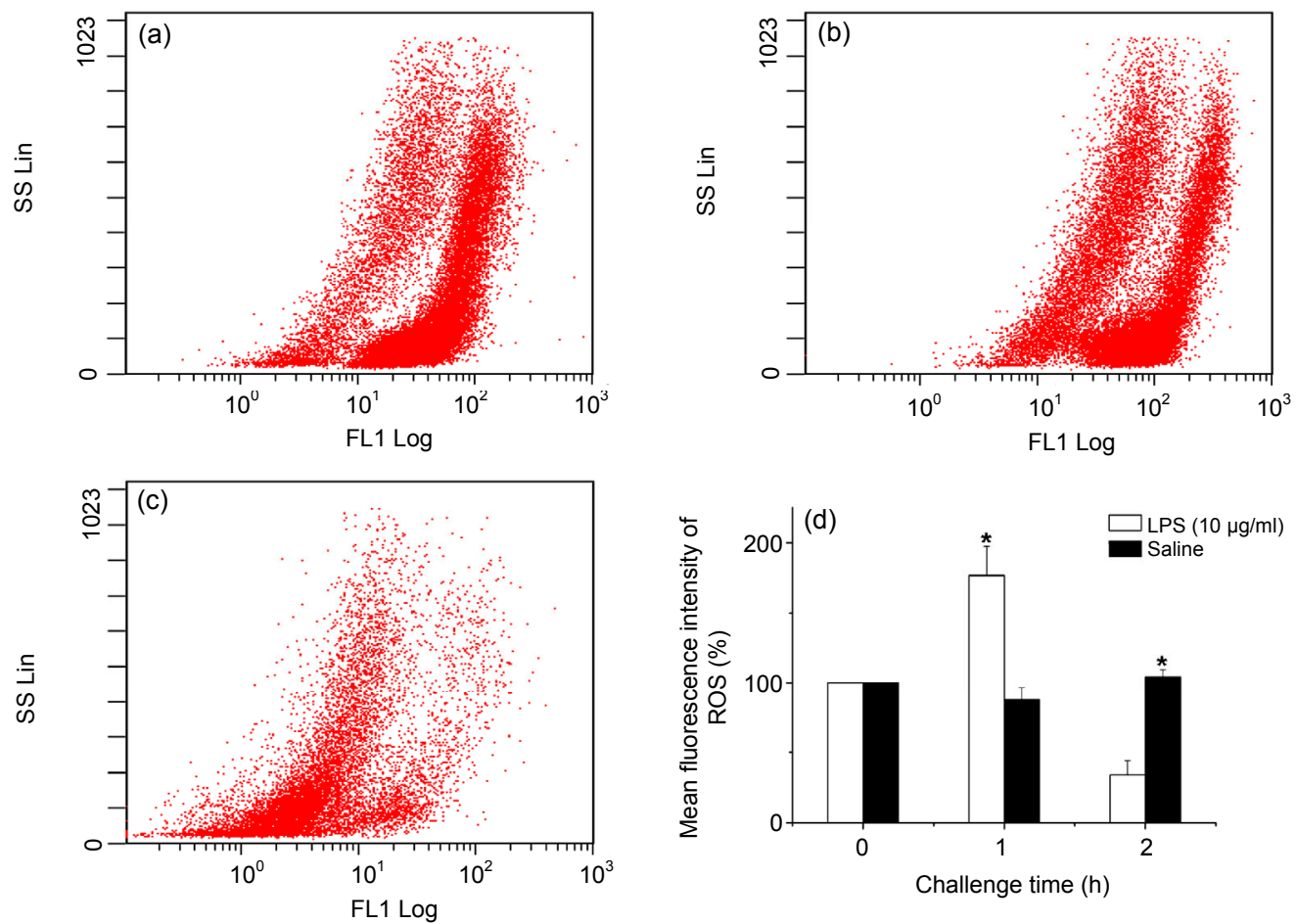

Fig. 5 Analysis of cellular ROS production of hemocytes treated with $10 \mu \mathrm{g} / \mathrm{ml}$ LPS by flow cytometry (a) Hemocytes treated for $0 \mathrm{~h}$; (b) Hemocytes treated for $1 \mathrm{~h}$; (c) Hemocytes treated for $2 \mathrm{~h}$. (d) Relative fluorescence intensity of ROS of hemocytes. Data presented are the means ( \pm standard deviation (SD)) of results from three independent experiments. The data indicated with '*' are significantly different $(P<0.05)$ among treatments in the same time point 


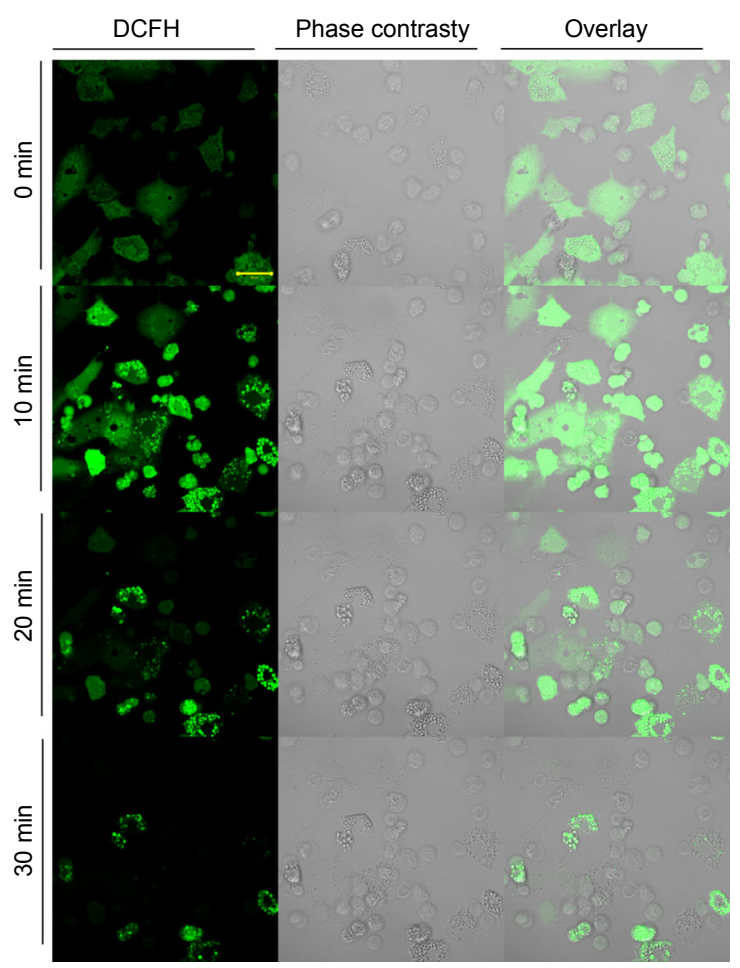

Fig. 6 Outburst of ROS production in LPS-induced hemocytes marked with DCFH-DA and detected by laser confocal microscopy

\section{Discussion}

Hemocytes play primary roles in immune response of crustaceans to invaded microbial pathogens and exterior stimulations. Previous publications demonstrated that the total and differential hemocyte counts dramatically declined and then slowly recovered to the initial level when the crustaceans were challenged with extrinsic stimulants, such as LPS, $\beta-1,3$-glucan, and bacterium (Persson et al., 1987; Cheng and Chen, 2001; Lv et al., 2014), although the time to reach the maximum depletion of hemocytes and the rate of the decreased hemocytes were speciesspecific (Lorenzon et al., 1999; Johansson et al., 2000). In the present study, we found that LPS not only induced serious damage on the hemocyte DNA but also affected the nucleus integrity, including the nuclear margination, condensation, and fragmentation of chromatin, and the formation of apoptotic bodies, which are the characteristics of the cells undergoing apoptosis. According to the DNA fragmentation analysis, the high concentration of LPS intended to induce the easier formation of typical
DNA ladder, whereas the low concentration indicated conventional apoptosis-concentration relationship. This result is consistent with our previous conclusion that high LPS concentration caused significant decline on the hemocyte counts of E. sinensis (Lv et al., 2014). Similarly, in other crustaceans, such as Macrobrachium rosenbergii, Crangon crangon, Palaemon elegans, Nephrops norvegicus, and Munida rugosa, the LPS was also verified to elicit the rapid and massive degranulation of hemocytes in vitro and the depletion of hemocytes in vivo (Persson et al., 1987; Cheng and Chen, 2001). Some researchers speculated that the decline in total and differential hemocyte counts was due to the migration of hemocytes from the hemocoele to the injection sites, hemocyte lysis, and granulocyte degranulation (Lv et al., 2014), which apparently cannot be supported by our finding. Challenging with LPS for $2 \mathrm{~h}$ resulted in different stages of apoptotic hemocytes and changed morphology. The images of fluorescence microscope and TEM showed that most hemocytes displayed cell shrinkage, chromatin condensation, and fragmentation without the breakdown of plasma membrane and a few of them formed visible apoptotic bodies. All of these are the obvious characteristics of cell undergoing apoptosis. A total of $75.01 \%$ hemocytes were detected to be the hemocytes undergoing apoptosis after challenged with $10 \mu \mathrm{g} / \mathrm{ml}$ LPS for $2 \mathrm{~h}$. In previous experiments, we demonstrated that the circulating hemocytes reached to its lowest level in vivo after challenged with $250 \mu \mathrm{g} / \mathrm{ml}$ LPS for $2 \mathrm{~h}$ with approximately $16.81 \%$ of total hemocytes accounted for (Lv et al., 2014). These findings further reveal that the disappearing hemocytes are correlated with the process of cell apoptosis.

ROS plays an important role in the elimination of pathogens, especially in the process of phagocytosis (Raman et al., 2008). ROS was determined to fluctuate under the stresses of nitrite (Xian et al., 2011), heavy metals (Xian et al., 2010), and exterior stimulants (Xian et al., 2013). In P. monodon, Xian et al. (2013) reported that the circulating hemocytes experienced a strong increase in ROS production after being challenged with LPS, indicating an obvious respiration burst. In the present study, treating with LPS induced an obvious outburst of ROS production with relatively high DCF mean fluorescence, which was similar to the phenomenon observed in P. monodon. Interestingly, nearly all the hemocytes experienced an obvious increase in DCF fluorescence after 
treatment with LPS, especially granule-containing hemocytes, such as semigranulocytes and granulocytes, which are verified to be two major kinds of hemocytes responsible for the storage and release of the proPO system. The active proPO (phenol oxidase) plays an important role in the process of respiratory burst (Johansson and Soderhall, 1989; Johansson et al., 2000). Based on the analysis of flow cytometry, we found that the circulating hemocytes of $E$. sinensis could be divided into two subpopulations with different DCF mean fluorescences: granule-containing hemocytes and non-granular hemocytes. Differing from previous studies, the ROS production was shown to decrease significantly over time in LPS-treated hemocytes, as observed in the present study using the laser confocal microscopy and flow cytometry. Previous publications proved that ROS could initiate intracellular signal transmission accompanied with the release of granules (degranulation) owning active phenol oxidase (Brinkmann and Zychlinsky, 2012; Pijanowski et al., 2013). In E. sinensis, we have verified that the stimulation of LPS on hemocytes induced a prominent boost of peroxinectin protein owning phenol oxidase followed with the remarkable release of incremental peroxinectin and granules into the extracellular matrix (Lv et al., 2015). The significant decrease in the ROS production might be due to the release of the phenol oxidase into the extracellular protein, such as peroxinectin. The difference in the time interval for the ROS decrease within these two inspection methods might be due to the situation of the hemocytes. The hemocytes used in the present study for microscopy observation were primarily cultured in a culture dish having sufficient contact of them with the LPS. Conventionally, the production of ROS in hemocytes is sensitive to the exterior stimulations, such as LPS. In the ROS-dependent systems, a small increase in ROS is considered to be beneficial to the innate immunity of crustaceans; however, the overproduction of ROS would cause oxidative damage to the hemocyte structure and even lead to cell apoptosis (Orrenius, 2007; Chang et al., 2009). Therefore, the overproduction of ROS is thought to be an important induction factor for the hemocyte apoptosis in E. sinensis.

The results of the present study clearly showed that the stimulation of LPS caused obvious apoptosis and ROS overproduction in hemocytes of $E$. sinensis. It is attested that the drastic decrease in hemocytes in E. sinensis by the treatment of LPS is correlated to the cell apoptosis. ROS directly induced the release of phenol oxidase-containing granules, which was beneficial to the innate immunity. Overproduction of ROS was an important induction factor for hemocyte apoptosis in E. sinensis. ROS-mediated apoptosis is probably the toxicity mechanism of LPS on crustacean hemocytes.

\section{Compliance with ethics guidelines}

Hai-sheng XU, Sun-jian LYU, Jie-hao XU, Bin-jie LU, Jing ZHAO, Song LI, Yi-qun LI, and Yu-yin CHEN declare that they have no conflict of interest.

All institutional and national guidelines for the care and use of laboratory animals were followed.

\section{References}

Brinkmann, V., Zychlinsky, A., 2012. Neutrophil extracellular traps: is immunity the second function of chromatin? $J$. Cell Biol., 198(5): 773-783. [doi:10.1083/jcb.201203170]

Chang, C.C., Yeh, M.S., Lin, H.K., et al., 2008. The effect of Vibrio alginolyticus infection on caspase-3 expression and activity in white shrimp Litopenaeus vannamei. Fish Shellfish Immunol., 25(5):672-678. [doi:10.1016/j.fsi. 2008.09.004]

Chang, M., Wang, W.N., Wang, A.L., et al., 2009. Effects of cadmium on respiratory burst, intracellular $\mathrm{Ca}^{2+}$ and DNA damage in the white shrimp Litopenaeus vannamei. Comp. Biochem. Phys. C, 149(4):581-586. [doi:10.1016/ j.cbpc.2008.12.011]

Cheng, W., Chen, J.C., 2001. Effects of intrinsic and extrinsic factors on the haemocyte profile of the prawn, Macrobrachium rosenbergii. Fish Shellfish Immunol., 11(1):53-63. [doi:10.1006/fsim.2000.0293]

Du, J., Zhu, H., Ren, Q., et al., 2012. Flow cytometry studies on the Macrobrachium rosenbergii hemocytes subpopulations and immune responses to novel pathogen spiroplasma MR-1008. Fish Shellfish Immunol., 33(4): 795-800. [doi:10.1016/j.fsi.2012.07.006]

Gai, Y., Zhao, J., Song, L., et al., 2008. A prophenoloxidase from the Chinese mitten crab Eriocheir sinensis: gene cloning, expression and activity analysis. Fish Shellfish Immunol., 24(2):156-167. [doi:10.1016/j.fsi.2007.08.006]

Jiravanichpaisal, P., Lee, B.L., Söderhäll, K., 2006. Cellmediated immunity in arthropods: hematopoiesis, coagulation, melanization and opsonization. Immunobiology, 211(4):213-236. [doi:10.1016/j.imbio.2005.10.015]

Johansson, M.W., Söderhäll, K., 1985. Exocytosis of the prophenoloxidase activating system from crayfish haemocytes. J. Comp. Physiol. B, 156(2):175-181. [doi:10.1007/ BF00695771]

Johansson, M., Soderhall, K., 1989. Cellular immunity in crustaceans and the proPO system. Parasitol. Today, 5(6): 171-176. [doi:10.1016/0169-4758(89)90139-7]

Johansson, M.W., Keyser, P., Sritunyalucksana, K., et al., 2000. Crustacean haemocytes and haematopoiesis. Aquaculture, 191(1):45-52. [doi:10.1016/S0044-8486(00)00418-X]

Khanobdee, K., Soowannayan, C., Flegel, T.W., et al., 2002. Evidence for apoptosis correlated with mortality in the 
giant black tiger shrimp Penaeus monodon infected with yellow head virus. Dis. Aquat. Org., 48(2):79-90. [doi:10. 3354/dao048079]

le Moullac, G., Haffner, P., 2000. Environmental factors affecting immune responses in Crustacea. Aquaculture, 191(1-3): 121-131. [doi:10.1016/S0044-8486(00)00422-1]

Li, C.C., Chen, J.C., 2008. The immune response of white shrimp Litopenaeus vannamei and its susceptibility to Vibrio alginolyticus under low and high $\mathrm{pH}$ stress. Fish Shellfish Immunol., 25(6):701-709. [doi:10.1016/j.fsi. 2008.01.007]

Lorenzon, S., de Guarrini, S., Smith, V.J., et al., 1999. Effects of LPS injection on circulating haemocytes in crustaceans in vivo. Fish Shellfish Immunol., 9(1):31-50. [doi:10. 1006/fsim.1998.0168]

Lv, S.J., Xu, J.H., Zhao, J., et al., 2014. Classification and phagocytosis of circulating haemocytes in Chinese mitten crab (Eriocheir sinensis) and the effect of extrinsic stimulation on circulating haemocytes in vivo. Fish Shellfish Immunol., 39(2):415-422. [doi:10.1016/j.fsi. 2014.05.036]

Lv, S.J., Lu, B.J., Xu, J.H., et al., 2015. Immune response of peroxinectin of Chinese mitten crab Eriocheir sinensis to exterior stimulation. Dev. Comp. Immunol., 51(1):56-64. [doi:10.1016/j.dci.2015.02.016]

Orrenius, S., 2007. Reactive oxygen species in mitochondriamediated cell death. Drug Metab. Rev., 39(2-3):443-455. [doi:10.1080/03602530701468516]

Persson, M., Cerenius, L., Söderhäll, K., 1987. The influence of haemocyte number on the resistance of the freshwater crayfish, Pacifastacus leniusculus Dana, to the parasitic fungus Aphanomyces astaci. J. Fish Dis., 10(6):471-477. [doi:10.1111/j.1365-2761.1987.tb01098.x]

Pijanowski, L., Golbach, L., Kolaczkowska, E., et al., 2013. Carp neutrophilic granulocytes form extracellular traps via ROS-dependent and independent pathways. Fish Shellfish Immunol., 34(5):1244-1252. [doi:10.1016/j.fsi. 2013.02.010]

Portt, L., Norman, G., Clapp, C., et al., 2011. Anti-apoptosis and cell survival: a review. Biochim. Biophys. Acta, 1813(1):238-259. [doi:10.1016/j.bbamcr.2010.10.010]

Raman, T., Arumugam, M., Mullainadhan, P., 2008. Agglutininmediated phagocytosis-associated generation of superoxide anion and nitric oxide by the hemocytes of the giant freshwater prawn Macrobrachium rosenbergii. Fish Shellfish Immunol., 24(3):337-345. [doi:10.1016/j.fsi. 2007.12.005]

Sahtout, A.H., Hassan, M., Shariff, M., 2001. DNA fragmentation, an indicator of apoptosis, in cultured black tiger shrimp Penaeus monodon infected with white spot syndrome virus (WSSV). Dis. Aquat. Org., 44(2):155-159. [doi:10.3354/dao044155]

van de Braak, C.B.T., Botterblom, M.H.A., Liu, W., et al., 2002. The role of the haematopoietic tissue in haemocyte production and maturation in the black tiger shrimp (Penaeus monodon). Fish Shellfish Immunol., 12(3): 253-272. [doi:10.1006/fsim.2001.0369]

Xian, J.A., Wang, A.L., Ye, C.X., et al., 2010. Phagocytic activity, respiratory burst, cytoplasmic free- $\mathrm{Ca}^{2+}$ concentration and apoptotic cell ratio of haemocytes from the black tiger shrimp, Penaeus monodon under acute copper stress. Comp. Biochem. Phys. C, 152(2):182-188. [doi:10. 1016/j.cbpc.2010.04.003]

Xian, J.A., Wang, A.L., Chen, X.D., et al., 2011. Cytotoxicity of nitrite on haemocytes of the tiger shrimp, Penaeus monodon, using flow cytometric analysis. Aquaculture, 317(1):240-244. [doi:10.1016/j.aquaculture.2011.03.026]

Xian, J.A., Miao, Y.T., Li, B., et al., 2013. Apoptosis of tiger shrimp (Penaeus monodon) haemocytes induced by Escherichia coli lipopolysaccharide. Comp. Biochem. Phys. A, 164(2):301-306. [doi:10.1016/j.cbpa.2012.10.008]

Zhang, Y., Zhao, J.M., Zhang, H., et al., 2010. The involvement of suppressors of cytokine signaling 2 (SOCS2) in immune defense responses of Chinese mitten crab Eriocheir sinensis. Dev. Comp. Immunol., 34(1):42-48. [doi:10.1016/j.dci.2009.08.001]

\section{中文概要}

题 目: 脂多糖对中华线鳌蟹血细胞调亡影响的研究

目 的: 评估细菌脂多糖 (LPS) 在体外环境下对中华线 螯蟹血细胞凋亡的影响，并探讨其诱导血细胞调 亡的机制。

创新点: 首次在体外条件下实验证明了 LPS 可诱导中华线 螯蟹血细胞的调亡, 并确定了活性氧自由基在细 胞凋亡过程中的变化和作用。

方 法: 在体外 $26^{\circ} \mathrm{C}$ 条件下, 培养中华线螯蟹血细胞。 用浓度 $1 \mu \mathrm{g} / \mathrm{ml}$ 的 LPS 处理血细胞 $0 、 4 、 8$ 和 $16 \mathrm{~h}$ 后，利用 4',6-二脒基-2-苯基吲哚（DAPI）染色、 苂光显微镜和透射电子显微镜观察血细胞的形 态变化, 用 DNA Ladder 试剂盒检测脱氧核糖核 酸 (DNA) 的损伤程度。分别用浓度 1 和 $10 \mu \mathrm{g} / \mathrm{ml}$ 的 LPS 处理血细胞 $0 、 1$ 和 $2 \mathrm{~h}$, 经膜联蛋白 V异硫氧酸荧光素 (V-FITC)/碘化丙啶 (PI) 染色 后, 用流式细胞仪检测血细胞凋亡数量。收集血 细胞制成细胞悬浮液, 加入 LPS 至终浓度为 $10 \mu \mathrm{g} / \mathrm{ml}$, 同时加入 $2^{\prime}, 7^{\prime}$-二氯荧光黄双乙酸盐 (DCFH-DA) 探针至终浓度为 $1 \mu \mathrm{mol} / \mathrm{L}$; 对照组 加入等量生理盐水和 DCFH-DA 探针。在 $26{ }^{\circ} \mathrm{C}$ 孵育不同时间后, 用流式细胞仪和激光共聚焦显 微镜检测血细胞活性氧的产生情况。

结 论: LPS 可诱导中华线螯蟹血细胞出现典型的调亡特 征, 包括染色质浓缩和边聚、核膜破裂、线粒体 肿胀、调亡小体形成等 (图 1 和 2), 形成明显 的 DNA 梯形条带 (图 3), 且细胞调亡数量与 LPS 浓度呈正相关, 大多数调亡细胞处于调亡晚 期（图 4）。活性氧检测结果显示: 经 LPS 刺激 后, 细胞内活性氧自由基信号显著增强, 随后又 迅速减弱（图 5 和 6)。综上所述, 体外 LPS 可 诱导中华线鳌蟹血细胞产生明显的调亡反应, 且 调亡过程伴随着显著的活性氧爆发。

关键词: 血细胞; 中华线螯蟹; 脂多糖; 调亡; 活性氧自 由基 